\title{
Novel report on six Fusarium species associated with head blight and crown rot of wheat in Basra province, Iraq
}

\author{
Mohammed Hussein Minati ${ }^{{ }^{*}}$ (D) and Mohanad Khalaf Mohammed-Ameen ${ }^{2}$
}

\begin{abstract}
Background: Wheat is the main cultivated crop and the highest cereal used up by humans in Iraq. Two Fusarium species causing Fusarium head blight (FHB) disease on wheat has been detected only in the middle of Iraq, and Fusarium crown rot (FCR) disease has been detected in several provinces, but it was limited to only three species. This study was conducted to deepen and enlarge our current understanding of the causal agents of these symptoms observed in the wheat fields and to isolate, purify, and identify (molecularly) the most common soil fungi occurring in the rhizosphere of seedlings showing, root, crown, stem, and head at symptom occurrence.

Results: Eighty-eight Fusarium isolates were isolated from 7 wheat cultivars planted in 14 fields in the south of Iraq, Basra province, by using polymerase chain reaction (PCR) technique. Based on molecular identification methods as well as the analysis of phylogenetic trees, the results of this study have verified that the main species belonging to the genus Fusarium causing FHB and FCR diseases on wheat in the studied areas are F. pseudograminearum, F. graminearum, F. equiseti, F. culmorum, F. solani, F. avenaceum, F. chlamydosporum, F. cerealis, and F. nygamai. The first 3 species have been identified previously in several Iraqi studies on wheat and barley. This is the first record of the last 6 Fusarium species from the wheat crop in Iraq as causative pathogens of FHB and FCR. Individual phylogenetic trees of 71 Fusarium isolates reconstructed based on the internal transcribed spacer (ITS) sequences showed that all isolates belonging to each of the 9 Fusarium species form monophyletic groups with identical isolates of the same species. Collective phylogenetic tree of the remaining 17 Fusarium isolates reconstructed based on translation elongation factor 1 alpha (TEF1-a) gene sequences showed that all isolates belonging to each of the 4 Fusarium species forms monophyletic groups with identical isolates of the same species.
\end{abstract}

Conclusion: Iraqi wheat cropping system is seriously threatened by FHB and FCR diseases. Other Iraqi provinces should be inspected to understand the distribution of both diseases.

Keywords: Cultivars, Identification, Morphology, Molecular, Phylogenetic tree

\section{Introduction}

Wheat (Triticum aestivum L. em. Thell) plays a noteworthy role in the world. More than 90 countries of the Third World are harboring a total population exceeding 4.5 billion wheat-consuming people as the basic carbohydrates (Braun et al. 2010). Bread wheat is the main cultivated crop and the highest cereal used up by humans in Iraq. In 2016, the harvested wheat area in Iraq was 920,096 ha, and the production quantity was 3,

\footnotetext{
*Correspondence: abo_azher70@yahoo.com

'Plant Pathology Laboratory, Department of Biology, College of Science,

Basra University, Basra, Iraq

Full list of author information is available at the end of the article
}

052,939 t (Food and Agriculture Organization of the United Nations (FAO) 2018).

Multiple Fusarium species are responsible for the two destructive wheat diseases: Fusarium head blight (FHB) and Fusarium crown rot (FCR). These two diseases are the most widespread cereal diseases that have presented in most regions all over the world. Also, they are the most detrimental diseases that infect wheat cropping systems and other cereal crops resulting in considerable yield losses every year (Smiley and Patterson 1996; Koch et al. 2006; Hogg et al. 2010).

The prevalent species accompanying these two diseases are Fusarium graminearum Schwabe, Fusarium 
culmorum (W.G. Smith) Saccardo, and Fusarium pseudograminearum, whereas Fusarium equiseti (Corda) Sacc., Fusarium avenaceum (Fries) Saccardo, Fusarium poae (Peck) Wollenw, Fusarium crookwellense Burgess, Nelson \& Toussoun, Fusarium sporotrichioides Scherb., Fusarium acuminatum (Ellis and Everh.), and Fusarium oxysporium Schlecht. Emend. Snyder \& Hansen have been identified as less commonly isolated species (Braithwaite et al. 1998; Bottalico and Perrone 2002; Monds et al. 2005).

Regarding FHB disease, also known as scab or ear blight, whiteheads, and pink mold, is mostly caused by Fusarium graminearum Schwabe (teleomorph: Gibberella zeae (Schwabe) Petch) (Wegulo et al. 2011). In addition to a complex of Fusarium species often associated with FHB disease, up to 16 Fusarium species have been isolated from infected wheat heads (Parry et al. 1995). The FCR disease is mainly caused by Fusarium pseudograminearum teleomorph: Gibberella coronicola (Aoki and O'Donnell 1999; Li et al. 2008). Along with Chakraborty et al. (2006), there are 11 species that could also cause FCR disease in some wheat cultivars.

Parry et al. (1995) stated that even though FHB and FCR mostly caused by the same Fusarium species, the relationship among them is still unclear. Identification of Fusarium species established upon the morphological characteristics detected on particular media is trustworthy methods (Burgess et al. 2001; Nelson et al. 1983), but it demands time and the necessary expertise; therefore, it is very difficult for non-specialist (Bluhm et al. 2002). Hence, the best diagnostic method for conclusive identification of Fusarium species is the polymerase chain reaction (PCR) techniques as molecular approaches (Niessen et al. 2004; Mulè et al. 2005; Demeke et al. 2005; Jurado et al. 2006).

To the best of our knowledge, F.pseudograminearum and F. graminearum causing FHB disease on wheat have been detected only in the middle of Iraq by Khudhair et al. (2015a). While FCR disease has been detected in several provinces in Iraq, it was limited to only three species, F. pseudograminearum, F. graminearum, and F. equiseti (Hameed et al. 2012; Khudhair et al. 2015b; Matny et al. 2017; Lahuf et al. 2018).

Bearing in mind all the above literatures on the wheat plant diseases and the field observation of the symptoms on wheat stem bases and reduction of the average wheat production associated with empty and head bleaching suspected to be pathogenic fungi belonging to the genus Fusarium such as FHB and FCR. This study was conducted to isolate, purify, and identify (molecularly) most fungi from the soil at the emerging seedling, root, crown, stem, head, and rhizosphere at symptom occurrence, and also to deepen and enlarge our current understanding of the causal agents of these symptoms observed in the wheat fields.

\section{Materials and methods \\ Description of study fields and sampling}

In 2017/2018, a total of 14 winter wheat fields in 7 districts of Basra province, i.e., Qurna/Mzeara'a (QM) $34^{\circ}$ 38' 66.5" N, 73 27' 40" E; Qurna Research Station (QRS) $34^{\circ} 36^{\prime} 51.8^{\prime \prime} \mathrm{N}, 73^{\circ} 54^{\prime} 41^{\prime \prime}$ E; Thagar/Al-Izz1 (TI1) $34^{\circ} 50^{\prime} 40.5^{\prime \prime} \mathrm{N}, 73^{\circ} 03^{\prime}$ 68" E; Thagar/Al-Izz2 (TI2) $34^{\circ} 54^{\prime}$ 92.1" N, 72 84' 09" E; Thagar/Al-Izz3 (TI3) $34^{\circ} 54^{\prime} 43.6^{\prime \prime} \mathrm{N}, 72^{\circ} 87^{\prime}$ 72" E; Thagar/Karakor (TK) $34^{\circ} 51^{\prime} 91.1^{\prime \prime} \mathrm{N}, 73^{\circ} 28^{\prime}$ 64" E; Dair (D) 34 09' 05.2" N, 74 48' 90" E; Nashwa (N) 34 $14^{\prime} 46.5^{\prime \prime} \mathrm{N}$, 74. 98' 04" E; Al-Modienh/Salih River (MSR) 34 24' 99.1" N, 70 76' 14" E, Al-Modienh/Salt Project (MSP) $34^{\circ} 22^{\prime} 68.9^{\prime \prime} \mathrm{N}, 70^{\circ} 89^{\prime} 05^{\prime \prime} \mathrm{E}$; Talha/marshland 1 (ML1) $34^{\circ} 15^{\prime} 00.7^{\prime \prime} \mathrm{N}, 71^{\circ} 49^{\prime} 14^{\prime \prime} \mathrm{E}$; Talha/marshland 2 (ML2) 34 $14^{\circ} 63.8^{\prime \prime} \mathrm{N}, 71^{\circ} 55^{\prime} 44^{\prime \prime} \mathrm{E}$; Al-Hammar Marsh (HM) 34 $07^{\prime} 68.9^{\prime \prime} \mathrm{N}, 71^{\circ} 52^{\prime} 68^{\prime \prime} \mathrm{E}$; and Huwair (H) 34 $36^{\prime} 08.9^{\prime \prime} \mathrm{N}, 71^{\circ} 58^{\prime} 79^{\prime \prime} \mathrm{E}$ at the north of Basra/south of Iraq (Fig. 1) were chosen for the isolation and identification of the fungi associated with the bleaching and yellowing symptoms of wheat plant terminals (heads, roots, and stems), which were most commonly observed during the last 10 years. The area of the 14 selected fields range between 15 and 100 ha.

\section{Spatial characterization of field infection}

All the 14 selected fields were geo-referenced through GBS sites. To allow for the possibility of specific determination for these sites, reference point was matched to the adjacent geographical location names distinguishable in the spatial database.

\section{Wheat cultivars}

Seven soft wheat winter cultivars (Abu Ghraib 3 (AG3), Ebaa-99 (I99), Adana 99 (A99, Turkey), Bengal (Barcelona (B.)), Research 22 (local (Res. 22)), Rasheed (local (R.)), and AGRI-saaten (AGRI S., Germany)) were planted in the 14 studied fields. The last cultivar was planted for the first time in the south of Iraq. These seven cultivars were selected to represent those frequently grown in Basra province/Southern Iraq.

\section{Sample collection Soil samples}

Soil samples were taken from the 14 selected fields at seedling emergence with a depth of $20-30 \mathrm{~cm}$. Five to 10 soil samples (depending on the field area) were collected from random locations within each field using a digging tool, sited in particular air-tight plastic collection sacks, and placed in an icebox for transferring to the 


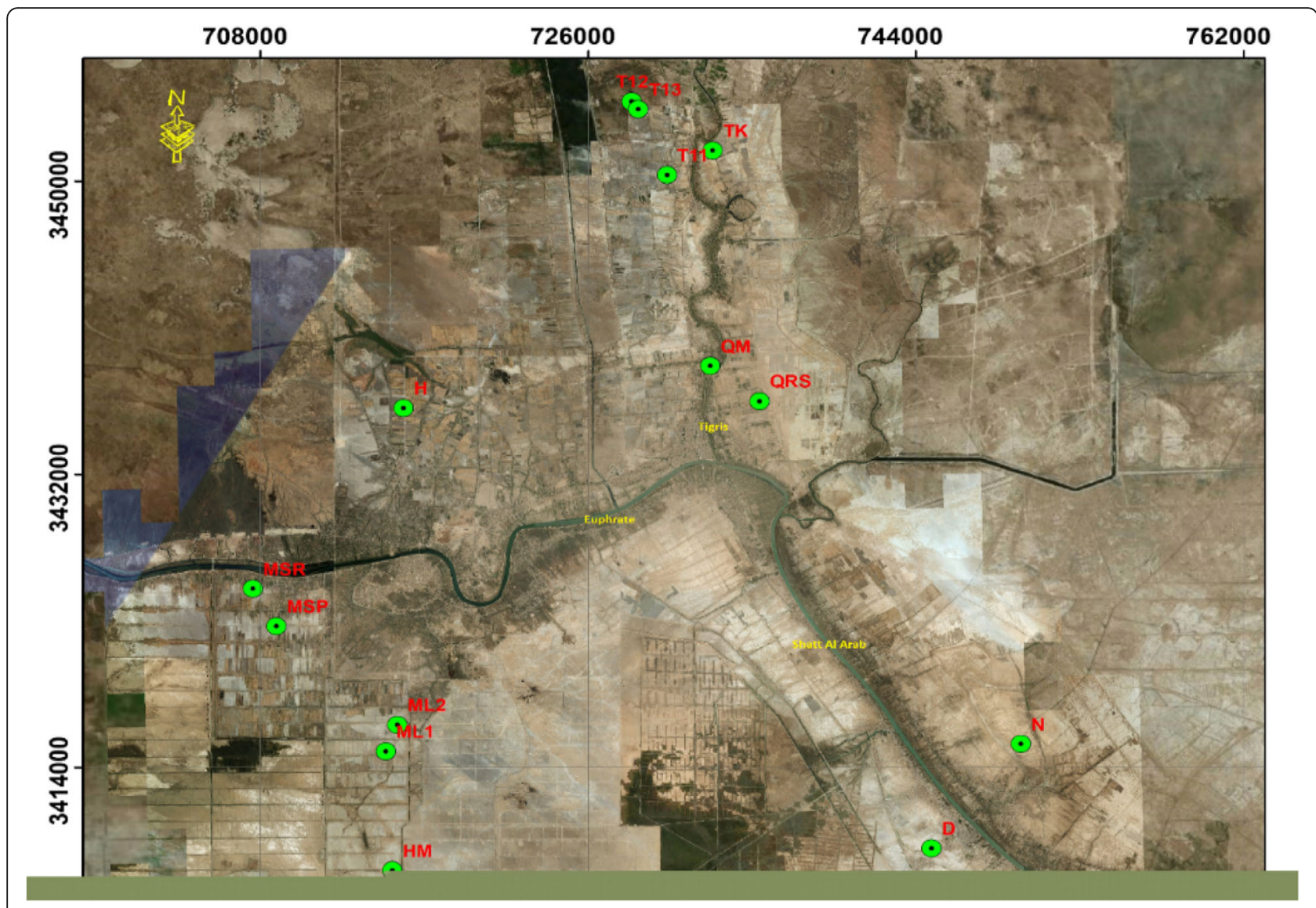

Fig. 1 Map of the south of Basra illustrating the 14 selected wheat fields where symptomatic wheat plants were collected in 2018/2019

laboratory. The soil samples were stored at $4{ }^{\circ} \mathrm{C}$ in the laboratory awaiting additional soil processing.

\section{Plant samples}

For every field, infected plants showing disease symptoms (blighted heads and stem tissues turned to tan or brown as well as senesce prematurely) were collected within 15-20 days before harvest (during the premature and ripening stage). In 2017/2018, samples were collected between April 5 and May 1. For every field, depending on field area, a complete 8-15 tillers/field were collected. At harvest time, the seeds from mature heads were individually collected, cautiously pulled off, combined, and air-dried. The seeds from each field were sited in polythene bags and stored in the dark at $10{ }^{\circ} \mathrm{C}$ before being tested in the experiments of fungal isolation.

Wheat plants with symptoms of partial or full whiteheads and crown and stem browning were collected (Figs. 2 and 3). These symptomatic plants with their
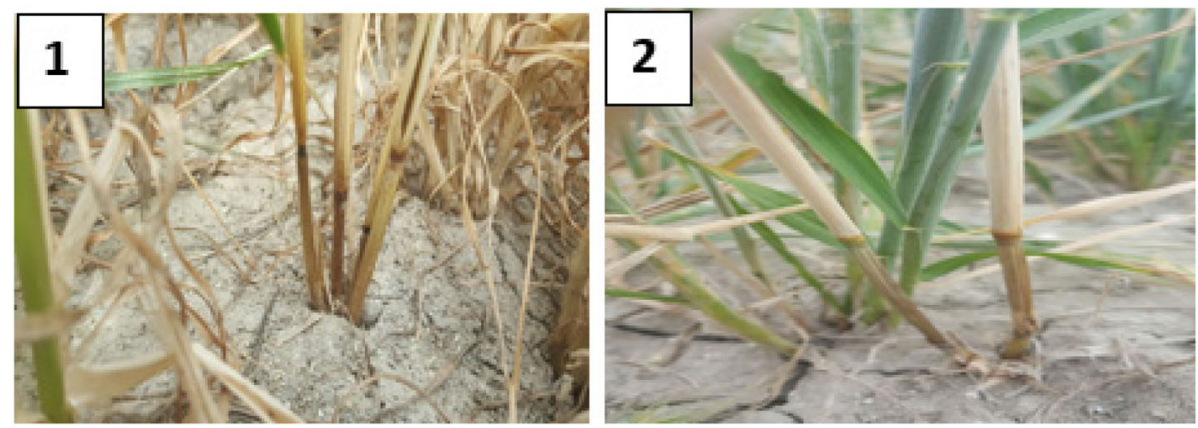

Fig. 2 Fusarium crown rot (FCR) symptoms at ripening time in $\mathbf{1}$ Talha (HM) and $\mathbf{2}$ Thagar (TI2) wheat fields. 


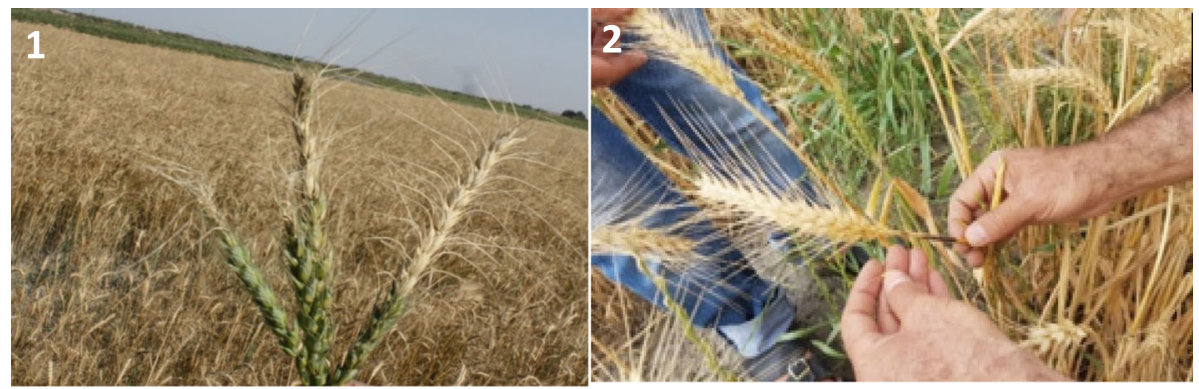

Fig. 3 Fusarium head blight (FHB) symptoms in $\mathbf{1}$ Qurna (QM) and $\mathbf{2}$ Talha (ML2) wheat field

roots and rhizosphere picked up from naturally diseased cultivated plants grows at the 14 selected fields in the south of Basra. All the samples were placed individually in air-tight plastic collection sacks in the fields, sited in a cool box for transferring to the laboratory, and stored at $4{ }^{\circ} \mathrm{C}$ for not more than 7 days before being tested.

\section{Isolation of fungi}

Each plant part (head, crown, stem base, and root) was thoroughly washed in running water for 10-15 min, soaked in $6 \%$ sodium hypochlorite for $2 \mathrm{~min}$, rinsed in sterile distilled water several times, and then air-dried on a filter paper, while wheat grains were sterilized by moistening with $70 \%$ ethanol for 2 min, soaking in $6 \%$ sodium hypochlorite for $1 \mathrm{~min}$, rinsing in sterile distilled water several times, and then air-dried on a filter paper. Then, they were placed in Petri dishes $(9 \mathrm{~cm})$ of fullstrength potato dextrose agar (PDA), rose Bengal agar (RBA), malt extract agar (MEA), Czapek Dox Agar (CZA), malachite green agar (MGA), and Sabouraud dextrose agar (SDA) with three replicates for each, five disinfected tissue pieces per Petri dish with 2:1:2 plant tissue arrangement, and seven grains/Petri plate in 2:3:2 arrangement. The Petri dishes were incubated at $25^{\circ} \mathrm{C} \pm$ 2 for 7-14 days and checked daily for fungal growth. For better sporulation and chlamydospore production, all isolates were sub-cultured onto water agar (WA), quarter-strength potato dextrose agar (QPDA), half-strength potato dextrose agar (HPDA), full-strength potato dextrose agar (PDA), and synthetic nutrient agar (SNA with $1 \mathrm{~cm}^{2}$ of sterilized filter paper placed onto the middle of it), with three replicates for each, incubated under similar conditions.

\section{Isolation from soil}

Several methods for soil dilution were employed in this study, i.e., malachite green agar (MGA), rose Bengal (RB), potato dextrose agar (PDA, Oxoid Limited) with chloroform, and dichloran rose Bengal agar (DRBC) base. Serial dilution of the collected soil samples ranging from $10^{-4}$ to $10^{-6}$ dilution using sterile distilled water and boiled sterile distilled water $\left(100^{\circ} \mathrm{C}\right)$ was carried out. For fungal isolation improvement, a sterilized pipette was used to transfer $1 \mathrm{ml}$ of every single dilution to the surface of the abovementioned media. The Petri dishes were then incubated for $3-5$ days at $25^{\circ} \mathrm{C} \pm 2$ for fungal growth and purified onto PDA, as the best media displaying clear structures for all fungal isolates during this study.

For identification, colony morphology and microscopic examinations of the obtained isolates of pure cultures were used to determine the structures of vegetation and reproduction. The identification was carried out morphologically to the genus level and molecularly to species.

\section{Molecular identification \\ DNA extraction}

Fungal genomic DNA prepared from a colony of each isolate was extracted using the Plant Genomic DNA Mini Kit (GP100) Geneaid protocol according to the manufacturer's instructions.

\section{DNA electrophoresis}

The process of DNA electrophoresis was performed according to Sambrook et al. (1989).

\section{Polymerase chain reaction amplification}

A total of 186 isolates of various fungal species from symptomatic wheat plants, their seeds, rhizosphere, and soil in the north of Basra were identified to genus or species based on the morphology, while 123 isolates out of the 186 isolates were molecularly identified to species by means of the PCR technique. The sequence of internal transcribed spacer (ITS) region was amplified using the universal primer pair ITS1 (F) ( $5^{\prime}$-TCC GTA GGT GAA CCT GCG G-3') and ITS4 (R) (5' ${ }^{\prime}$ TCC TCC GCT TAT TGA TAT GC-3').

Amplification of genomic DNA was executed in a total volume of $25 \mu \mathrm{l}$ consist of $5 \mu \mathrm{l}$ Master Mix (Bioneer, Korea), $1.5 \mu \mathrm{l}$ of each primer, $5 \mu \mathrm{l}$ of the genomic DNA as a template, and $12 \mu \mathrm{l}$ deionized sterile distilled water. 
PCR reactions were accomplished in a Thermo-cycler (MyGenie96 Thermal Block, Bioneer, Korea) and the amplification program initiated with denaturation at $95^{\circ} \mathrm{C}$ for activating the tag-polymerase for $5 \mathrm{~min}$, followed by 35 cycles of 30 -s denaturation at $95^{\circ} \mathrm{C}, 30 \mathrm{~s}$ of annealing at $60{ }^{\circ} \mathrm{C}$, and $45 \mathrm{~s}$ of extension at $72{ }^{\circ} \mathrm{C}$ with final extension at $72{ }^{\circ} \mathrm{C}$ for $5 \mathrm{~min}$. In the last part, $1.5 \%$ agarose gel electrophoresis was dissolved in $1 \times$ Tris-borate-EDTA (TBE) buffer, stained with ethidium bromide, visualized under a UV transilluminator, and photographed by GeneSnap photo imaging system (SynGene).

\section{DNA sequencing}

The sequences of ITS1-5.8S rDNA and the purification for the amplified PCR products of 123 isolates were conducted in (MACROGEN Company, South Korea) "http://dna.macrogen.com." The obtained sequences were compared with those available in GeneBank and NCBI http://www.ncbi.nlm.nih.gov employing BLAST. Established upon the closest identification of BLAST analysis, 17 isolates from the Fusarium genus were matched in less than $97 \%$ of similarity with high expected values and inadequate maximum scores. As a result, the genomic DNA of these 17 Fusarium isolates were again amplified, purified, and sequenced using the translation elongation factor $1 \alpha$ (TEF1- $\alpha)$ gene with primers EF-1 (5-'ATG GGT AAG GAG GAC AAG AC-3') and EF-2 (5'-GGA AGT ACC AGT GAT CAT GTT-3') as follows.

Amplification of genomic DNA was executed similar to that done for the ITS region. The amplification program initiated with denaturation at $95^{\circ} \mathrm{C}$ to activate the tag-polymerase for $5 \mathrm{~min}$, followed by 35 cycles of 30-s denaturation at $95^{\circ} \mathrm{C}, 30 \mathrm{~s}$ of annealing at $51.5^{\circ} \mathrm{C}$, and $90 \mathrm{~s}$ of extension at $72{ }^{\circ} \mathrm{C}$ with final extension at $72{ }^{\circ} \mathrm{C}$ for $7 \mathrm{~min}$. The purified PCR products of the 17 Fusarium isolates then sent to the same commercial company for sequencing in bi-directions using the above particular forward and reverse primers (EF-1 and EF-2).

\section{Analysis of ITS region and TEF1-a gene for Fusarium species} The evolutionary history of all Fusarium spp. was concluded by using the maximum likelihood method and Kimura 2-parameter model (Kimura 1980). Initial trees for the heuristic search were achieved by applying the neighbor-joining method (nearest-neighbor interchange (NNI)). The evolutionary distances were computed using the maximum composite likelihood (MCL) approach, and the neighbor-joining tree reliabilities were estimated by the bootstrap method with 1100 replications. Evolutionary analyses were conducted in MEGA 7 (Kumar et al. 2018). Aspergillus niveus (MH865978.1) and Alternaria ventricosa (KM454880.1) sequences from GenBank were selected as the out-group.

\section{Results \\ Molecular identification based on ITS1 and ITS4 primer pairs}

Established upon the closest identification of BLAST analysis, the obtained nucleotide sequences of 123 isolates were compared to the GenBank databases and matched at diverse global similarity.

\section{Molecular identification of Fusarium spp.}

Our results of morphological investigation in association with DNA sequencing consistent with the first matching identification of BLAST sequence database in NCBI using distinct sequences proved the identity of 88 isolates out of the total 123 isolates that belong to the genus Fusarium in 9 species (F. pseudograminearum, $F$. graminearum, F. culmorum, F. chlamydosprum, F. equiseti, F. solani, F. avenaceum, F. cerealis, and F. nygamai). Seventy-one sequences of these isolates corresponded to the GenBank databases at $97-100 \%$ as global similarity (Additional file 1), whereas the remaining 17 Fusarium isolate sequences were matched to the published sequences that deposited in the GenBank sequence database in less than $97 \%$ of similarity with high expected values and inadequate maximum scores.

Therefore, the 71 Fusarium isolates deposited in the GenBank nucleotide databases under accession numbers MK271097-MK271110 for Fusarium chlamydosporum (14 isolates), MK271111-MK271115 for Fusarium equiseti (5 isolates), MK271231-MK271238 for Fusarium solani (8 isolates), MK271239-MK271246 for Fusarium pseudograminearum (8 isolates), MK271247-MK271265 for Fusarium graminearum (19 isolates), MK271266MK271269 for Fusarium avenaceum (4 isolates), MK271270-MK271271 for Fusarium cerealis (2 isolates), MK281297-MK281306 for Fusarium culmorum (10 isolates), and MK271272 for Fusarium nygamai (one isolate) (Table 1).

\section{Sequencing of TEF1-a gene}

Established upon the closest identification of BLAST analysis, the obtained nucleotide sequences of the 17 sequences of Fusarium isolates were compared to the GenBank databases and matched at 99-100\% (Table 2).

The results based on ITS sequences showed that only six isolates (ITS-22 (Fus-2), ITS-78 (Fus-11), ITS-85 (Fus-13), ITS-102 (Fus18), ITS-111 (Fus-20), and ITS117 (Fus-22)) were similar in identification as indicated by the partial TEF1- $\alpha$ gene sequences, but with different percentage of identity. The first isolate (ITS-22) was identified as Fusarium pseudograminearum, and the latter isolates (ITS-78, ITS-85, ITS-102, ITS-111, and ITS-117) belong to Fusarium culmorum, whereas the remaining 11 isolates were completely different in identification. 
Table 1 Identification of Fusarium taxa isolated from the selected wheat fields based on the sequencing of rDNA ITS1-5.8S-ITS4 region

\begin{tabular}{|c|c|c|c|c|c|c|c|}
\hline Isolate & $\begin{array}{l}\text { NCBI Blast } \\
\text { identification }\end{array}$ & Accession no. & \% ID & Field & Source & Primer & E.V \\
\hline $\mathrm{TS}-3$ & F. chlamydosporum & MK271097 & 100 & $\mathrm{~N}$ & Head & ITS1 & 0.0 \\
\hline ITS-6 & F. nygamai & MK271272 & 100 & $N$ & Root & ITS1 & 0.0 \\
\hline ITS-7 & F. equiseti & MK271114 & 100 & $\mathrm{~N}$ & Root & ITS1 & 0.0 \\
\hline ITS-8 & F. chlamydosporum & MK271104 & 100 & $N$ & Root & ITS1 & 0.0 \\
\hline ITS-10 & F. equiseti & MK271115 & 100 & QM & Root & ITS1 & 0.0 \\
\hline ITS-13 & F. chlamydosporum & MK271105 & 100 & $\mathrm{HM}$ & Root & ITS1 & 0.0 \\
\hline ITS-14 & F. equiseti & MK271111 & 100 & $\mathrm{H}$ & Head & ITS1 & 0.0 \\
\hline ITS-15 & F. chlamydosporum & MK271100 & 100 & $\mathrm{HM}$ & Stem & ITS1 & 0.0 \\
\hline ITS-19 & F. graminearum & MK271263 & 100 & $\mathrm{~T} 13$ & Rhizo & ITS1 & 0.0 \\
\hline ITS-20 & F. pseudograminearum & MK271243 & 100 & MSR & Root & ITS1 & 0.0 \\
\hline ITS-21 & F. culmorum & MK281297 & 100 & $\mathrm{D}$ & Head & ITS1 & 0.0 \\
\hline ITS-23 & F. pseudograminearum & MK271241 & 100 & MSR & Stem & ITS1 & 0.0 \\
\hline ITS-24 & F. pseudograminearum & MK271246 & 100 & TK & Seed & ITS1 & 0.0 \\
\hline ITS-29 & F. solani & MK271231 & 100 & TI1 & Head & ITS1 & 0.0 \\
\hline ITS-30 & F. solani & MK271232 & 100 & $\mathrm{D}$ & Head & ITS1 & 0.0 \\
\hline ITS-33 & F. graminearum & MK271264 & 100 & $N$ & Rhizo & ITS1 & 0.0 \\
\hline ITS-34 & F. avenaceum & MK271268 & 100 & MSP & Root & ITS1 & 0.0 \\
\hline ITS-35 & F. avenaceum & MK271267 & 100 & $N$ & Stem & ITS1 & 0.0 \\
\hline ITS-36 & F. graminearum & MK271248 & 100 & $\mathrm{H}$ & Stem & ITS1 & 0.0 \\
\hline ITS-37 & F. graminearum & MK271249 & 100 & QRS & Stem & ITS1 & 0.0 \\
\hline ITS-38 & F. graminearum & MK271250 & 100 & QRS & Stem & ITS1 & 0.0 \\
\hline ITS-39 & F. graminearum & MK271259 & 100 & $\mathrm{~N}$ & Root & ITS1 & 0.0 \\
\hline ITS-40 & F. culmorum & MK281298 & 100 & $\mathrm{HM}$ & Stem & ITS1 & 0.0 \\
\hline ITS-41 & F. chlamydosporum & MK271106 & 100 & $\mathrm{HM}$ & Root & ITS1 & 0.0 \\
\hline ITS-42 & F. chlamydosporum & MK271107 & 100 & LM1 & Root & ITS1 & 0.0 \\
\hline ITS-43 & F. chlamydosporum & MK271109 & 100 & $\mathrm{HM}$ & Rhizo & ITS1 & 0.0 \\
\hline ITS-52 & F. solani & MK271235 & 100 & $\mathrm{Tl} 1$ & Stem & ITS1 & 0.0 \\
\hline ITS-54 & F graminearum & MK271260 & 100 & LM2 & Root & ITS1 & 0.0 \\
\hline ITS-56 & F. avenaceum & MK271269 & 100 & $\mathrm{Tl} 3$ & Rhizo & ITS1 & 0.0 \\
\hline ITS-57 & F. chlamydosporum & MK271101 & 100 & MSP & Stem & ITS1 & 0.0 \\
\hline ITS-59 & F. graminearum & MK271265 & 100 & LM2 & Rhizo & ITS1 & 0.0 \\
\hline ITS-63 & F. culmorum & MK281299 & 100 & $\mathrm{D}$ & Head & ITS1 & 0.0 \\
\hline ITS-64 & F. graminearum & MK271261 & 100 & $\mathrm{Tl} 3$ & Root & ITS1 & 0.0 \\
\hline ITS-67 & F. graminearum & MK271247 & 100 & QRS & Head & ITS1 & 0.0 \\
\hline ITS-68 & F. pseudograminearum & MK271239 & 100 & $\mathrm{TI} 1$ & Head & ITS1 & 0.0 \\
\hline ITS-69 & F. culmorum & MK281300 & 100 & $\mathrm{~T} 13$ & Rhizo & ITS1 & 0.0 \\
\hline ITS-71 & F. graminearum & MK271251 & 100 & $\mathrm{Tl} 3$ & Stem & ITS1 & 0.0 \\
\hline ITS-72 & F. chlamydosporum & MK271102 & 100 & $\mathrm{~T} 12$ & Stem & ITS1 & 0.0 \\
\hline ITS-73 & F. solani & MK271236 & 100 & $\mathrm{TI} 2$ & Root & ITS1 & 0.0 \\
\hline ITS-74 & F. culmorum & MK281301 & 100 & $\mathrm{~T} 12$ & Root & ITS1 & 0.0 \\
\hline ITS-75 & F. culmorum & MK281302 & 100 & MSP & Stem & ITS1 & 0.0 \\
\hline ITS-77 & F. culmorum & MK281303 & 100 & MSP & Root & ITS1 & 0.0 \\
\hline ITS-79 & F. culmorum & MK281304 & 100 & $\mathrm{~T} 13$ & Stem & ITS1 & 0.0 \\
\hline
\end{tabular}


Table 1 Identification of Fusarium taxa isolated from the selected wheat fields based on the sequencing of rDNA ITS1-5.8S-ITS4 region (Continued)

\begin{tabular}{|c|c|c|c|c|c|c|c|}
\hline Isolate & $\begin{array}{l}\text { NCBI Blast } \\
\text { identification }\end{array}$ & Accession no. & $\%$ ID & Field & Source & Primer & $\overline{E . V}$ \\
\hline ITS-80 & F. pseudograminearum & MK271244 & 100 & $\mathrm{TI3}$ & Root & ITS1 & 0.0 \\
\hline ITS-86 & F. equiseti & MK271113 & 100 & $\mathrm{HM}$ & Stem & ITS1 & 0.0 \\
\hline ITS-88 & F. chlamydosporum & MK271098 & 100 & LM1 & Head & ITS1 & 0.0 \\
\hline ITS-92 & F. solani & MK271238 & 100 & QM & Rhizo & ITS1 & 0.0 \\
\hline ITS-94 & F. chlamydosporum & MK271108 & 100 & $\mathrm{~N}$ & Root & ITS1 & 0.0 \\
\hline ITS-97 & F. chlamydosporum & MK271103 & 100 & QM & Stem & ITS1 & 0.0 \\
\hline ITS-99 & F. culmorum & MK281305 & 100 & ML2 & Root & ITS1 & 0.0 \\
\hline ITS-103 & F. graminearum & MK271252 & 100 & QRS & Stem & ITS1 & 0.0 \\
\hline ITS-105 & F. graminearum & MK271253 & 100 & $\mathrm{~T} 13$ & Stem & ITS1 & 0.0 \\
\hline ITS-106 & F. pseudograminearum & MK271240 & 100 & LM1 & Head & ITS1 & 0.0 \\
\hline ITS-107 & F. pseudograminearum & MK271245 & 100 & LM2 & Root & ITS1 & 0.0 \\
\hline ITS-108 & F. pseudograminearum & MK271242 & 100 & MSP & Stem & ITS1 & 0.0 \\
\hline ITS-109 & F. graminearum & MK271254 & 100 & LM2 & Stem & ITS1 & 0.0 \\
\hline ITS-110 & F. graminearum & MK271262 & 100 & $N$ & Root & ITS1 & 0.0 \\
\hline ITS-112 & F. cerealis & MK271270 & 100 & QRS & Root & ITS1 & 0.0 \\
\hline ITS-114 & F. graminearum & MK271255 & 100 & QRS & Stem & ITS1 & 0.0 \\
\hline ITS-115 & F. cerealis & MK271271 & 100 & QRS & Root & ITS1 & 0.0 \\
\hline ITS-118 & F. culmorum & MK281306 & 100 & QRS & Root & ITS1 & 0.0 \\
\hline ITS-119 & F. equiseti & MK271112 & 100 & LM1 & Head & ITS1 & 0.0 \\
\hline ITS-122 & F. graminearum & MK271256 & 100 & $\mathrm{~T} 12$ & Stem & ITS1 & 0.0 \\
\hline ITS-123 & F. graminearum & MK271257 & 100 & $\mathrm{~T} 12$ & Stem & ITS1 & 0.0 \\
\hline ITS-125 & F. graminearum & MK271258 & 100 & $\mathrm{H}$ & Stem & ITS1 & 0.0 \\
\hline ITS-126 & F. avenaceum & MK271266 & 100 & $\mathrm{D}$ & Head & ITS1 & 0.0 \\
\hline ITS-129 & F. solani & MK271237 & 100 & $\mathrm{Tl1}$ & Root & ITS1 & 0.0 \\
\hline ITS-130 & F. solani & MK271233 & 100 & $\mathrm{TI} 1$ & Head & ITS1 & 0.0 \\
\hline ITS-131 & F. chlamydosporum & MK271110 & 100 & TK & Soil & ITS1 & 0.0 \\
\hline ITS-142 & F. cf. solani & MK271234 & 100 & TI1 & Head & ITS1 & 0.0 \\
\hline ITS-146 & F. chlamydosporum & MK271099 & 100 & TK & Head & ITS1 & 0.0 \\
\hline
\end{tabular}

The expectation value (describes the number of different alignments you may expect to see fortuitously when searching a database of a certain size) $\% I D$ percentage of identity, E.V E value

\section{Phylogenetic analyses of ITS region}

Individual evolutionary analysis of the obtained nine $\mathrm{Fu}$ sarium species (F. pseudograminearum, F. graminearum, F. culmorum, F. chlamydosprum, F. equiseti, F. solani, F. avenaceum, F. cerealis, and F. nygamai) contained within nucleotide sequences from a number of valid and verified DNA sequences together with the sequences of current study executed using MEGA X software program (Kumar et al. 2018).

\section{Analysis of ITS region for Fusarium species}

Polymerase chain reaction (PCR) analysis was established by using universal primers (ITS1 and ITS4) to confirm the quality of DNA amplification from 71 Iraqi Fusarium isolates. A DNA fragment of the ITS region for these 71 obtained Fusarium isolates varied ranging between 456 and $650 \mathrm{bp}$. According to White et al. (1990), the length of the obtained DNA fragment had the ideal conditions for amplification. Analysis of BLASTn establish on this region attributes $97-100 \%$ global similarities of query coverage identity with the ITS sequences of 9 species belonging to Fusarium genus (Table 1). In order to reconstruct the ITS trees, multiple alignment of $\approx 550 \mathrm{bp}$ segment of ITS gene for a number of various Fusarium taxa. ITS sequences of Aspergillus niveus (MH865978) and Alternaria ventricosa (KM454880) were used as the out-group species.

The phylogenetic trees of the 71 Fusarium isolates reconstructed based on ITS sequences, using neighborjoining analysis, showed that all isolates belonging to each of the 9 Fusarium species form monophyletic 
Table 2 Identification of 17 Fusarium taxa isolated from the selected wheat fields based on the sequencing of TEF1-a gene region in bidirectional and ITS1-5.8 rDNA-ITS4

\begin{tabular}{|c|c|c|c|c|c|c|}
\hline Isolate & $\begin{array}{l}\text { NCBI Blast identification } \\
\text { based on TEF primers }\end{array}$ & Accession no. & $\% \mathrm{ID}$ & $\begin{array}{l}\text { NCBI Blast identification } \\
\text { based on ITS primers }\end{array}$ & Accession no. & $\% \mathrm{ID}$ \\
\hline Fus-2 & F. pseudograminearum & MG670360.1 & 99 & F. pseudograminearum & MH865930.1 & 95 \\
\hline Fus-5 & F. pseudograminearum & MG570082.1 & 100 & F. culmorum & MH828227.1 & 94 \\
\hline Fus-6 & F. culmorum & MG670244.1 & 100 & F. pseudograminearum & MH715262.1 & 88 \\
\hline Fus-7 & F. culmorum & MG670244.1 & 100 & Fusarium sp. & KY931512.1 & 95 \\
\hline Fus-8 & F. culmorum & GU370472.1 & 99 & Fusarium sp. & JQ756987.1 & 80 \\
\hline Fus-9 & F. culmorum & MG670244.1 & 99 & F. pseudograminearum & МH333076.1 & 80 \\
\hline Fus-10 & F. pseudograminearum & MG570082.1 & 100 & F. asiaticum & KY272788.1 & 94 \\
\hline Fus-11 & F. culmorum & MG670244.1 & 99 & F. culmorum & KJ466109.1 & 95 \\
\hline Fus-13 & F. culmorum & MG670244.1 & 100 & F. culmorum & MH864973.1 & 87 \\
\hline Fus-15 & F. equiseti & KP881271.1 & 100 & Fusarium sp. & FJ840527.1 & 80 \\
\hline Fus-16 & F. pseudograminearum & MG570082.1 & 100 & F. culmorum & KF889093.1 & 89 \\
\hline Fus-17 & F. pseudograminearum & MG570082.1 & 100 & F. graminearum & KY426415.1 & 87 \\
\hline Fus-18 & F. culmorum & JF740860.1 & 100 & F. culmorum & MH864973.1 & 93 \\
\hline Fus-20 & F. culmorum & MG670244.1 & 100 & F. culmorum & MH864973.1 & 86 \\
\hline Fus-22 & F. culmorum & MG670244.1 & 100 & F. culmorum & KP726896.1 & 92 \\
\hline Fus-23 & F. equiseti & KT224322.1 & 99 & Fusarium sp. & KU693456.1 & 96 \\
\hline Fus-25 & F. solani & MH300508.1 & 99 & Fusarium sp. & KF293367.1 & 94 \\
\hline
\end{tabular}

$\% I D$ percentage of identity

groups with identical isolates of the same species. The phylogenetic trees displayed that the 14 isolates of $F$. chlamydosporum, 5 isolates of $F$. equiseti, 19 isolates of $F$. graminearum, 4 isolates of $F$. avenaceum, 10 isolates of F. culmorum, 8 isolates of $F$. solani, 8 isolates of $F$. pseudograminearum, 2 isolates of F. cerealis, and 1 isolate of $F$. nygamai clustered with a number of reference isolates of the F. chlamydosporum, F. equiseti, F. graminearum, F. avenaceum, F. culmorum, F. solani, F. pseudograminearum, $F$. cerealis, and $F$. nygamai, respectively (Figs. 4, 5, 6, 7, 8, 9, 10, 11, and 12).

\section{Phylogenetic analyses of TEF1-a gene}

Collective evolutionary analysis of the obtained four $\mathrm{Fu}$ sarium species (F. pseudograminearum, F. culmorum, $F$. equiseti, and F. solani) contained within nucleotide sequences from a number of valid and verified DNA sequences together with the sequences of current study executed using MEGA X software program (Kumar et al. 2018).

\section{Analysis of TEF1-a gene for Fusarium species}

The length of TEF1- $\alpha$ gene for the 17 obtained Fusarium isolates ranges between 670 and $740 \mathrm{bp}$. The analysis of BLASTn established on this region attributes 99-100\% global similarities of query coverage identity with bidirectional of the EF-1F and EF-2R sequences of four Fusarium species (F. culmorum, F. equiseti, $F$. pseudograminearum, and F. solani) (Table 2). In order to reconstruct the TEF1- $\alpha$ gene trees, multiple alignment of $\approx 750$ bp segment of TEF1- $\alpha$ gene for a number of various Fusarium taxa. TEF1- $\alpha$ gene sequence of Alternaria tenuissima (LC136861.1) was used as the outgroup species.

The collective phylogenetic tree of the 17 Fusarium isolates reconstructed based on TEF1- $\alpha$ gene sequences, using neighbor-joining analysis, showed that all isolates belonging to each of the 4 Fusarium species form monophyletic groups with identical isolates of the same species (Fig. 13). The phylogenetic tree displayed that the 2 isolates of F. equiseti, 9 isolates of F. culmorum, 1 isolate of $F$. solani, and 5 isolates of $F$. pseudograminearum clustered with a number of reference isolates of the $F$. equiseti, F. culmorum, F. solani, and F. pseudograminearum, respectively.

\section{Discussion}

Based on molecular identification methods as well as the analysis of phylogenetic trees, the results of this study have verified that the main species belonging to the genus Fusarium isolated and identified from wheat cropping system causing FHB and FCR diseases in the south of Iraq, Basra province, Iraq, are F. graminearum, F. culmorum, F. pseudograminearum, F. solani, F. equiseti, F. avenaceum, F. chlamydosporum, F. cerealis, and F. nygamai. 


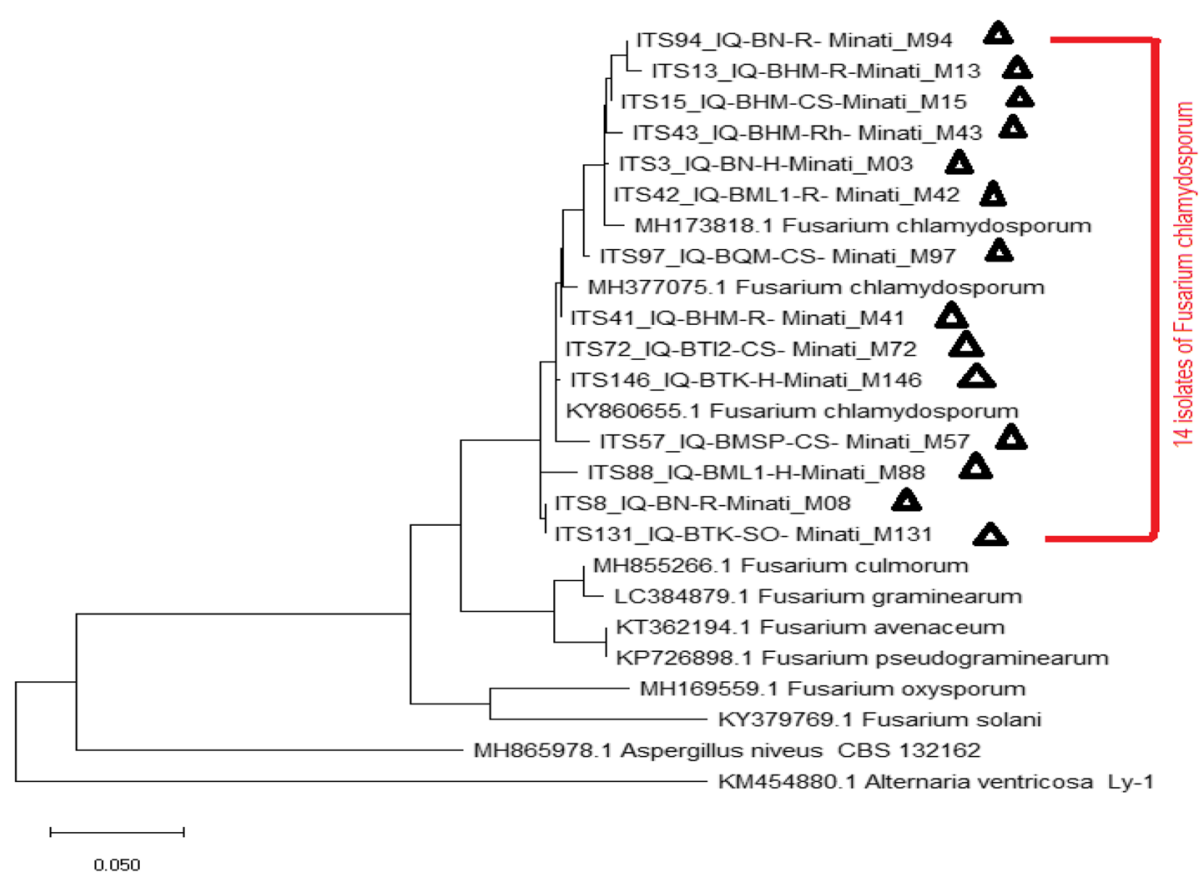

Fig. 4 Phylogenetic tree generated with the ITS-rDNA sequences of the Fusarium chlamydosporum (14), as inferred from the maximum likelihood (ML) analyses (determined by black triangles) and related species retrieved from GenBank. ITS sequences of Aspergillus niveus (MH865978) and Alternaria ventricosa (KM454880) were used as the out-group species

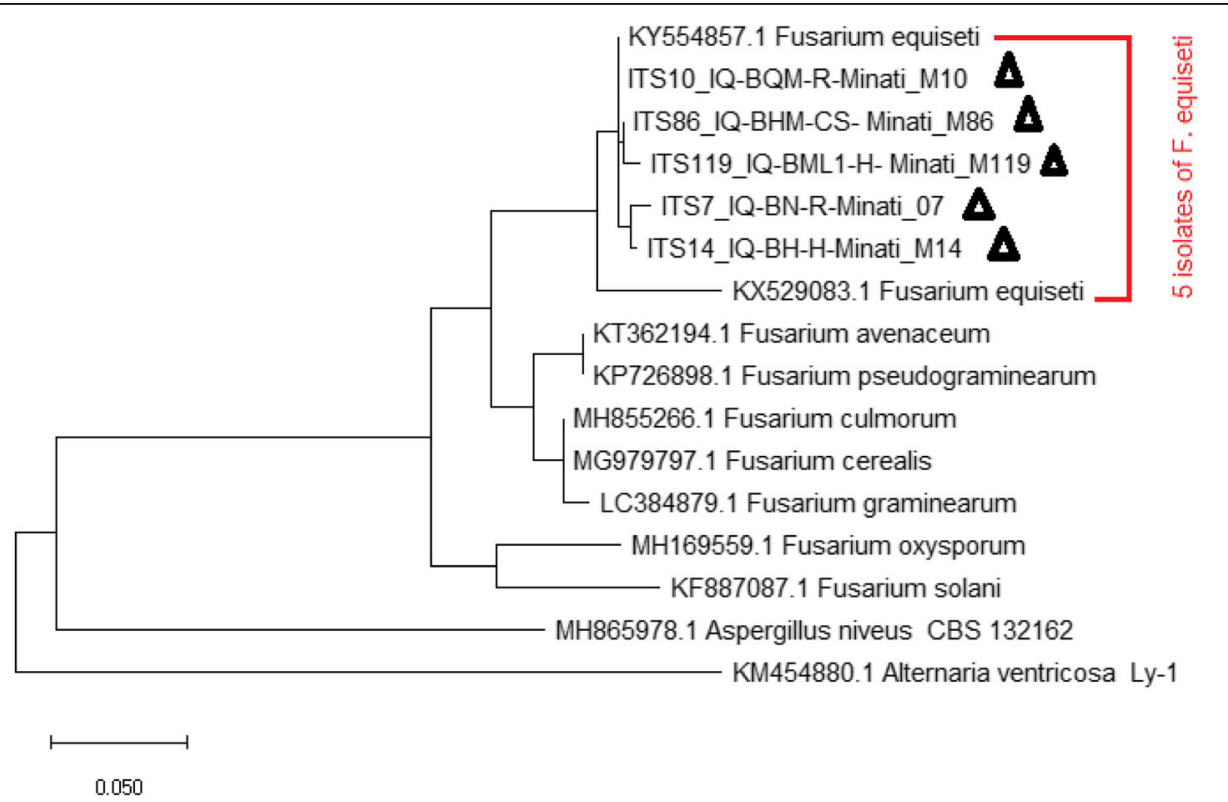

Fig. 5 Phylogenetic tree generated with the ITS-rDNA sequences of the Fusarium equiseti (5), as inferred from the maximum likelihood (ML) analyses (determined by black triangles) and related species retrieved from GenBank. ITS sequences of Aspergillus niveus (MH865978) and Alternaria ventricosa (KM454880) were used as the out-group species 


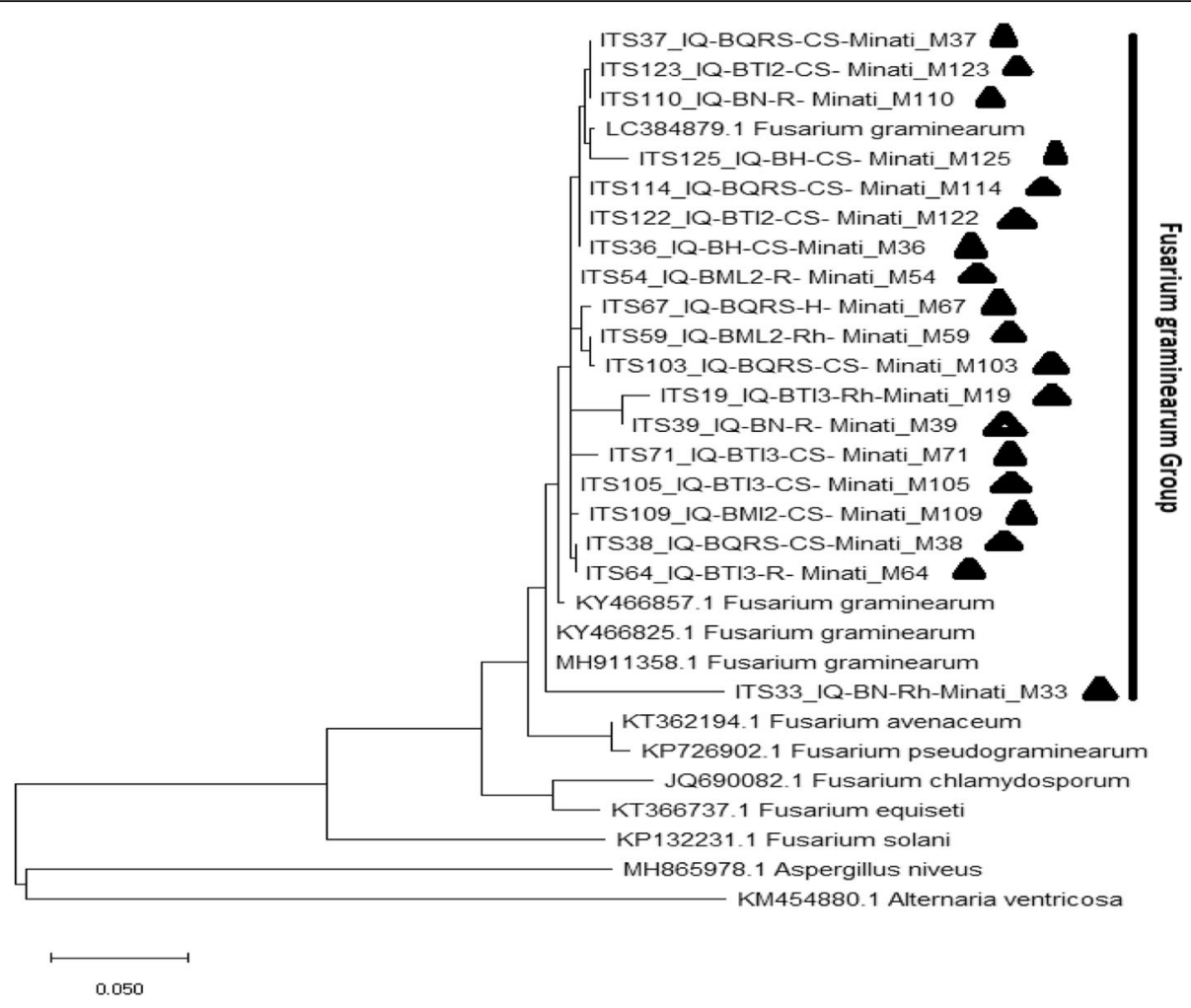

Fig. 6 Phylogenetic tree generated with the ITS-rDNA sequences of the Fusarium graminearum (19), as inferred from the maximum likelihood (ML) analyses (determined by black triangles) and related species retrieved from GenBank. ITS sequences of Aspergillus niveus (MH865978) and Alternaria ventricosa (KM454880) were used as the out-group species

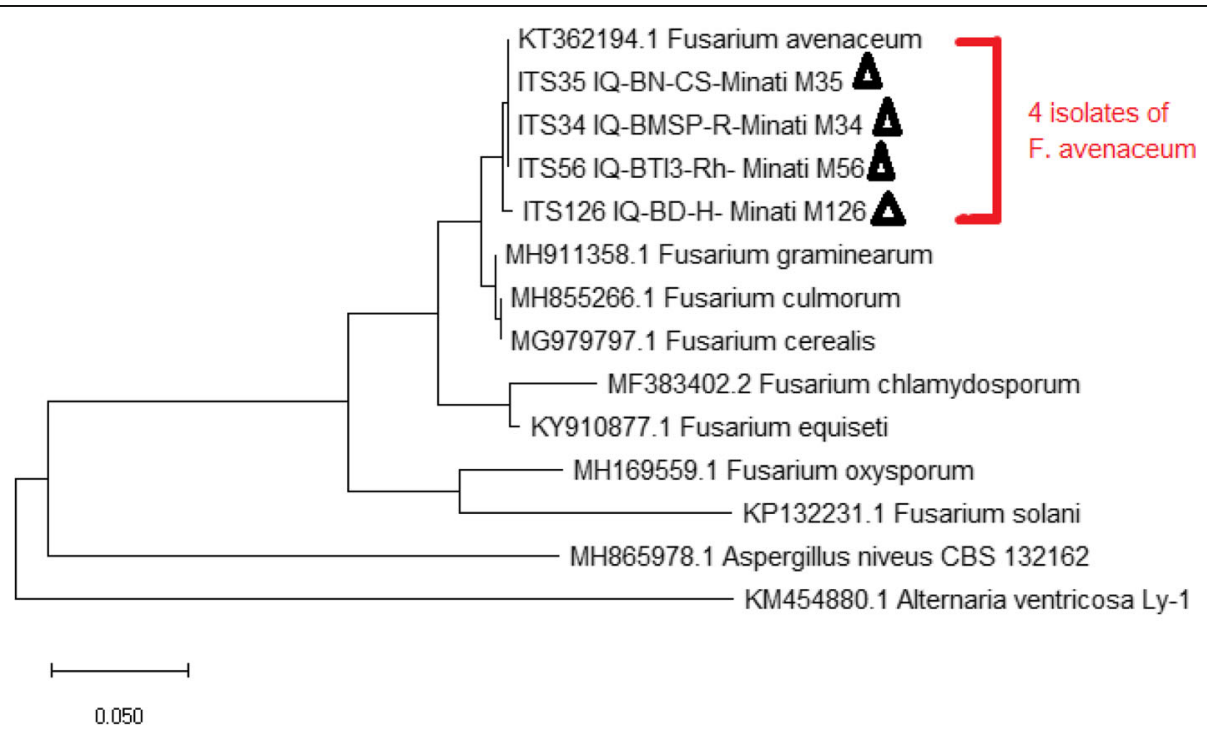

Fig. 7 Phylogenetic tree generated with the ITS-rDNA sequences of the Fusarium avenaceum (4), as inferred from the maximum likelihood (ML) analyses (determined by black triangles) and related species retrieved from GenBank. ITS sequences of Aspergillus niveus (MH865978) and Alternaria ventricosa (KM454880) were used as the out-group species 


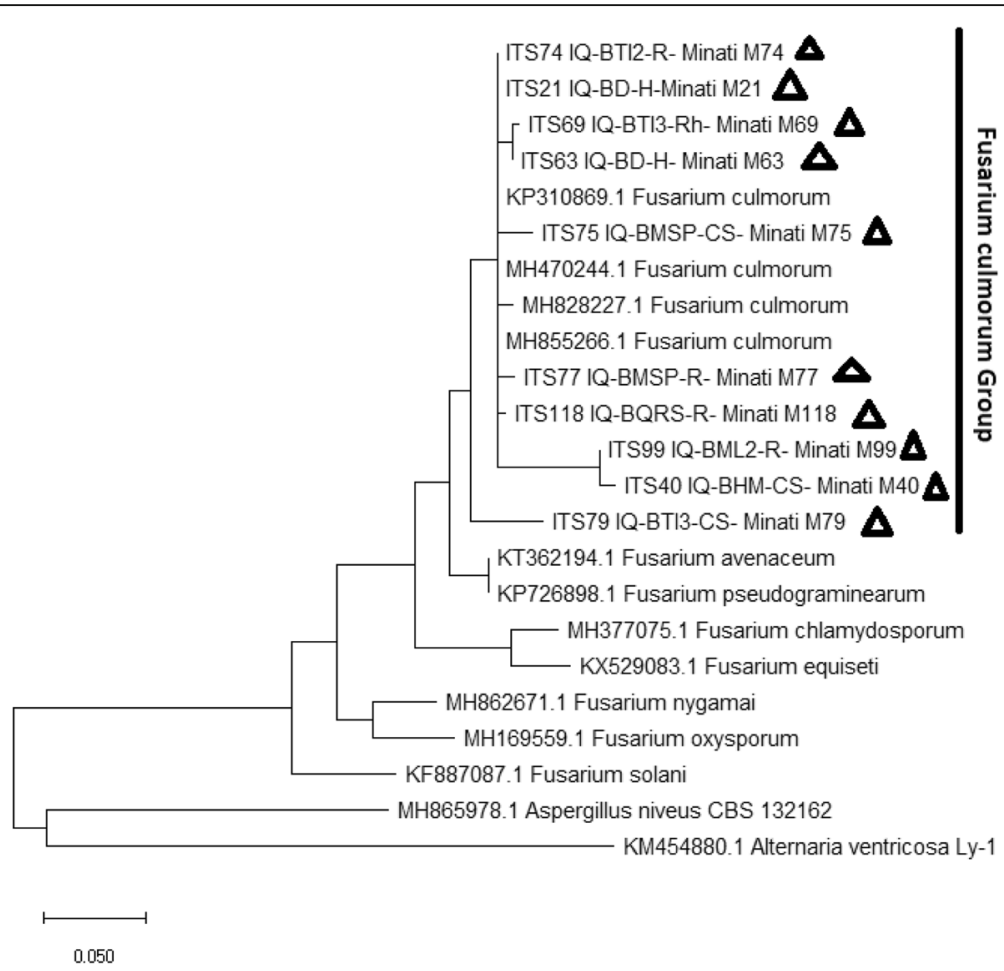

Fig. 8 Phylogenetic tree generated with the ITS-rDNA sequences of the Fusarium culmorum (10), as inferred from the maximum likelihood (ML) analyses (determined by black triangles) and related species retrieved from GenBank. ITS sequences of Aspergillus niveus (MH865978) and Alternaria ventricosa (KM454880) were used as the out-group species

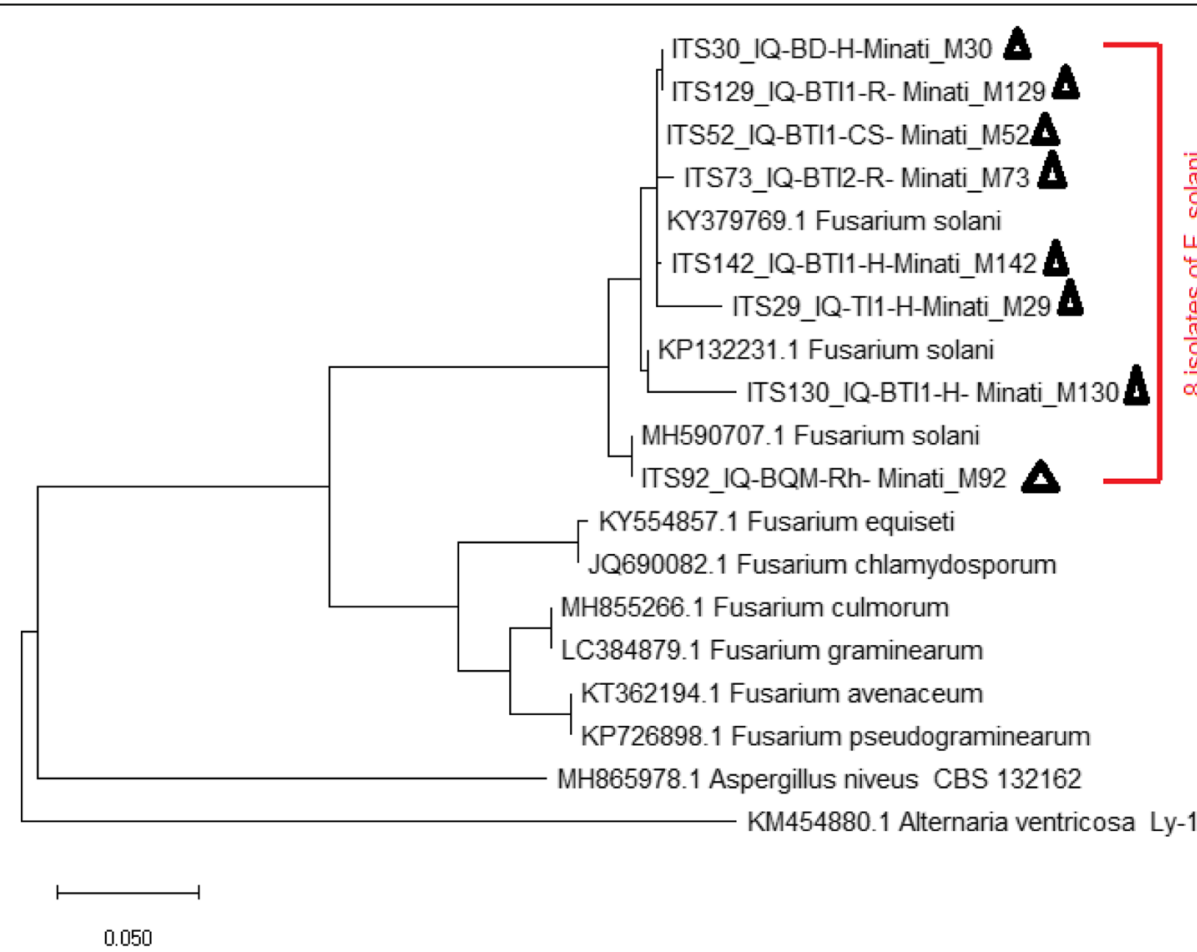

Fig. 9 Phylogenetic tree generated with the ITS-rDNA sequences of the Fusarium solani (8), as inferred from the maximum likelihood (ML) analyses (determined by black triangles) and related species retrieved from GenBank. ITS sequences of Aspergillus niveus (MH865978) and Alternaria ventricosa (KM454880) were used as the out-group species 


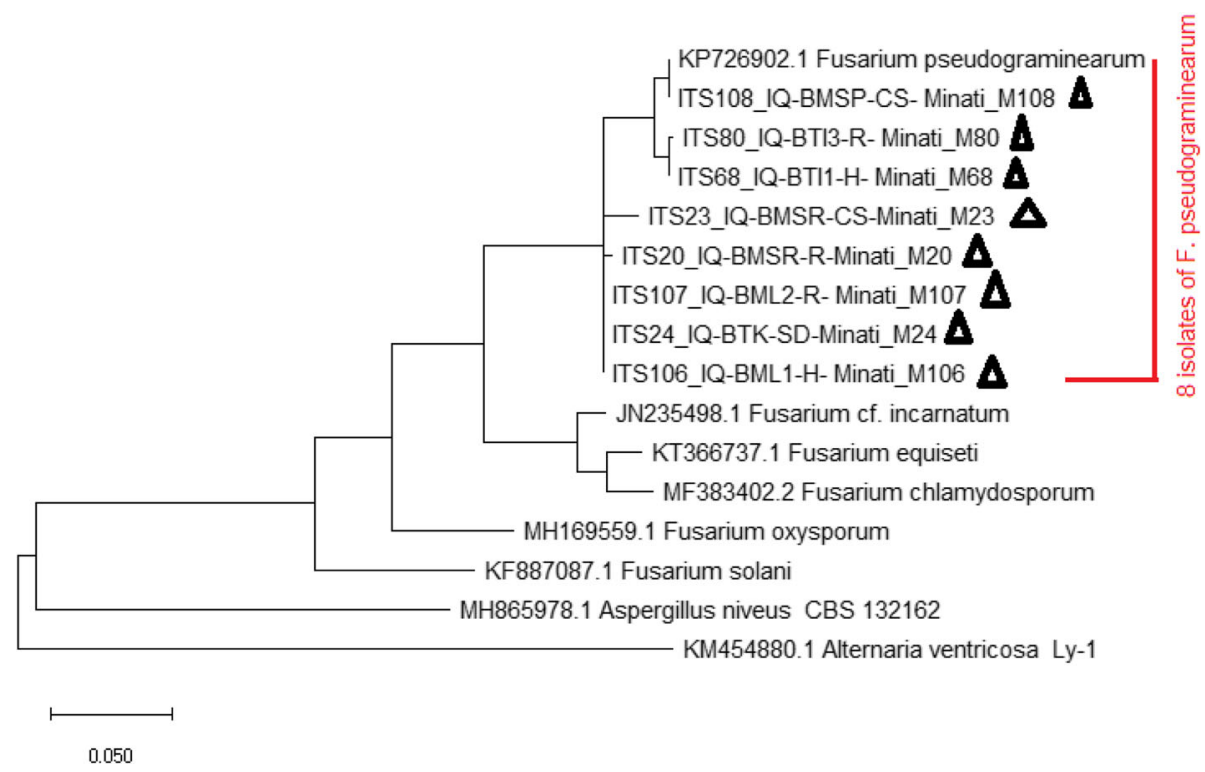

Fig. 10 Phylogenetic tree generated with the ITS-rDNA sequences of the Fusarium pseudograminearum (8), as inferred from the maximum likelihood (ML) analyses (determined by black triangles) and related species retrieved from GenBank. ITS sequences of Aspergillus niveus (MH865978) and Alternaria ventricosa (KM454880) were used as the out-group species

In previous Iraqi studies, three species of the genus Fusarium (F. pseudograminearum, F. graminearum, and F. equiseti) have been isolated and identified from wheat and barley as causative pathogens of FCR disease by Hameed et al. (2012), Matny et al. (2012), Khudhair et al. (2014), Khudhair et al. (2015a), Matny et al. (2017), and Lahuf et al. (2018). However, to the best of our knowledge, this is the first isolation and identification of the six new Fusarium species (F. culmorum, F. chlamydosporum, $F$. solani, $F$. avenaceum, $F$. cerealis, and $F$. nygamai) from the wheat crop in Iraq as causative pathogens of FHB and FCR.
In relation to $\mathrm{FCR}$, as mentioned earlier, it is mainly caused by F. pseuograminearum (Aoki and O'Donnell 1999; Li et al. 2008). Akinsanmi et al. (2004) cited by (Chakraborty et al. 2006) pointed out that there are 10 species including $F$. avenaceum, F. graminearum, $F$. proliferatum, F. subglutinans, F. tricinctum, F. acuminatum, F. babinda, F. crookwellense, F. pseudograminearum, and $F$. torulosum that could also cause FCR disease in wheat cultivars.

Consequently, it can be clearly stated that our result is in accordance with the earlier published Iraqi studies on the occurrence of F.pseudograminearum, F. graminearum,

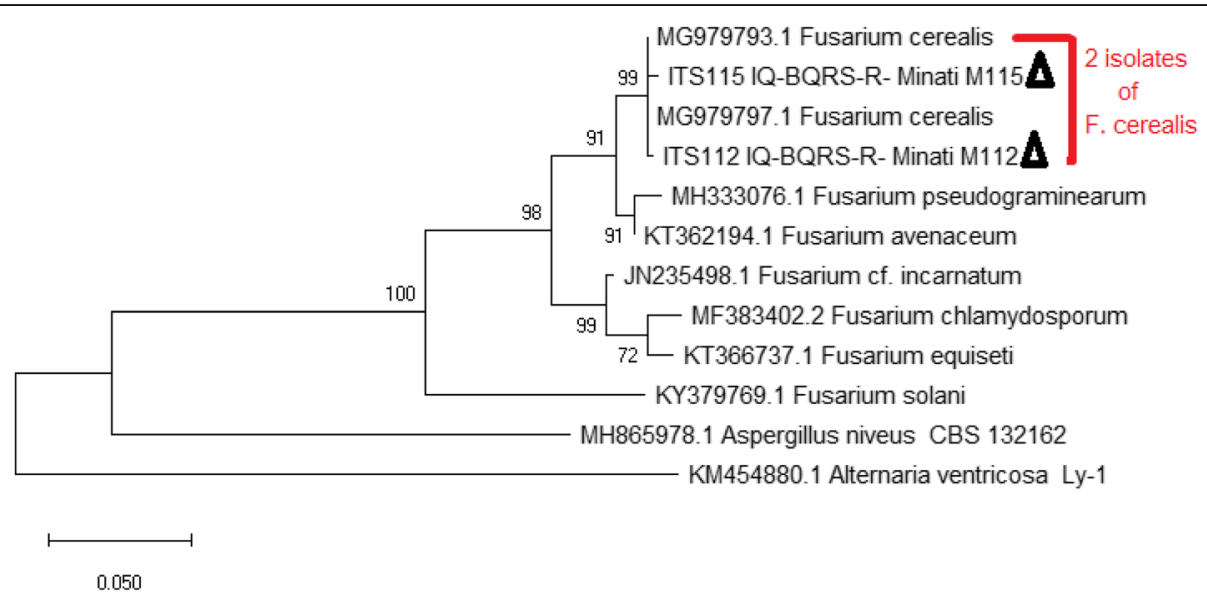

Fig. 11 Phylogenetic tree generated with the ITS-rDNA sequences of the Fusarium cerealis (2), as inferred from the maximum likelihood (ML) analyses (determined by black triangles) and related species retrieved from GenBank. ITS sequences of Aspergillus niveus (MH865978) and Alternaria ventricosa (KM454880) were used as the out-group species 


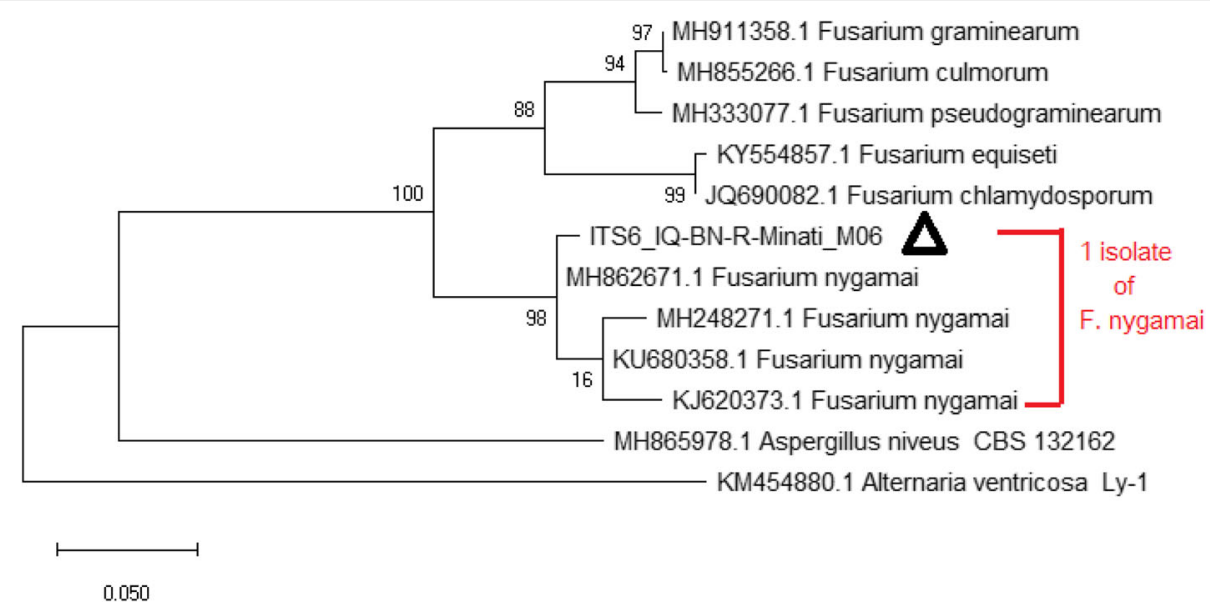

Fig. 12 Phylogenetic tree generated with the ITS-rDNA sequence of the Fusarium nygamai (1), as inferred from the maximum likelihood (ML) analyses (determined by black triangles) and related species retrieved from GenBank. ITS sequences of Aspergillus niveus (MH865978) and Alternaria ventricosa (KM454880) were used as the out-group species

and F. equiseti in wheat cropping system as causal pathogens of FCR disease. Moreover, we identified and recorded six Fusarium spp. (F. solani, F. chlamydosporum, F. avenaceum, F. culmorum, F. cerealis, and F. nygamai) as new causative pathogens of FCR disease in wheat cropping system in Iraq.

In terms of FHB, to the best of our knowledge, FHB disease on wheat has not yet been detected in all of wheat-harvested areas of the south of Iraq, Basra province. Importantly, in this study, we isolated and identified seven Fusarium spp. (F. solani, F. culmorum, F. pseudograminearum, F. equiseti, F. graminearum, F. avenaceum, and $F$. chlamydosporum) from wheat head to be recorded for the first time in Iraq as causal pathogens of FHB disease.

Even though Fusarium graminearum is known to be the main cause of FHB on wheat worldwide (Wegulo et al. 2011), there are another 16 Fusarium species (as a complex of these species) often isolated from the wheat crop in Australia and other countries, which could cause FHB disease on wheat as well (Parry et al. 1995). The distribution of these FHB causal pathogens globally

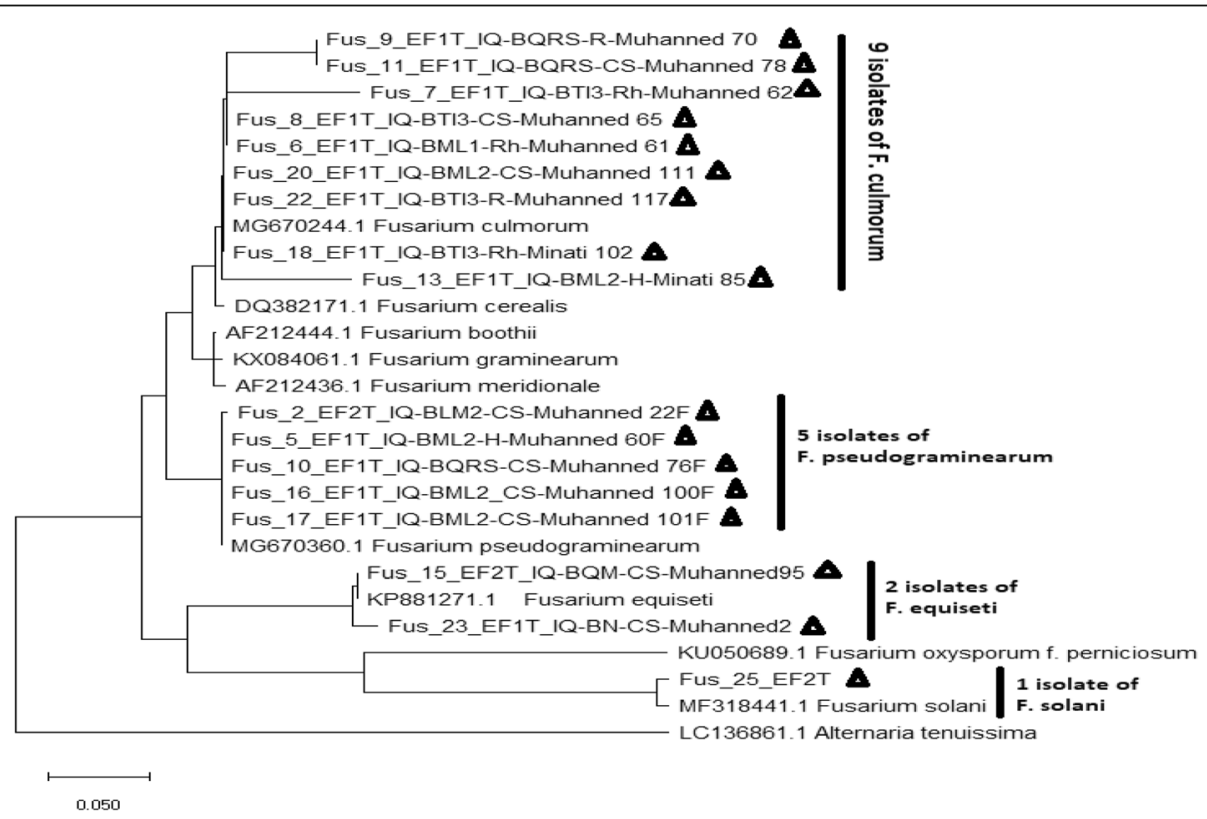

Fig. 13 Phylogenetic tree generated with the TEF1-a sequences of the 17 Fusarium isolates, as inferred from the maximum likelihood (ML) analyses (determined by black triangles) and related species retrieved from GenBank. TEF1-a gene sequence of Alternaria tenuissima (LC136861.1) was used as the out-group species 
differs in occurrence among the harvested wheat areas and is affected by the weather and environmental conditions. More frequently, some or all these pathogens can occur concurrently in wheat heads (Xu and Nicholson 2009). Worldwide, F. graminearum is the most occurring species associated with FHB disease (Leslie and Summerell 2006, Leslie \& Summerell, 2008), as it has been recognized in Europe, South and North America, and Asia. Other causal agents producing FHB have also been documented in Australia, Europe, and Asia (Xu and Nicholson 2009; Gale et al. 2002; Gale 2003; Gale et al. 2007; Alvarez et al. 2010).

The noticeable occurrence of FHB and FCR diseases in wheat- and barley-harvested areas in Iraq during the last few years associated with the obvious alteration in weather conditions represented by fluctuated temperature and high humidity companied with rainfall density and distribution. Additionally, the periodical increase of these two diseases in the last a few years might be attributed to the applying of impracticable agricultural practices, such as sowing uncertified seeds, conservation tillage, retaining wheat debris in the fields, and continuous winter wheat cropping without effective crop rotation (Khudhair et al. 2014). As stated by Lamprecht et al. (2006), opportunity of FCR disease can increase when using continuous wheat cropping in the same fields.

\section{Conclusion}

According to the obtained results, the Iraqi wheat cropping system is seriously threatened by FHB and FCR diseases. Seven Fusarium spp. were isolated from wheat head to be recorded for the first time in Iraq as causal pathogens of FHB disease, while nine Fusarium spp. were identified as causative pathogens of FCR disease. Further studies on these FHB and FCR causal pathogens in the Iraqi wheat cropping system should be conducted evaluating the potential yield losses and cultivar tolerance and determining mycotoxin produced. Likewise, it is necessary to survey the remaining Iraqi provinces especially the north and middle of Iraq to understand the distribution of both diseases and their responses to the different geographies and weather conditions.

\section{Additional file}

Additional file 1: Identification of general fungal taxa (123) isolated from symptomatic head, stem, root, seed and rhizosphere as well as from soil of the 14 selected fields based on morphological analysis and sequencing of rDNA ITS1-5.8S-ITS4 region during this study. (DOCX $40 \mathrm{~kb})$

\section{Abbreviations}

A99: Adana 99; AG3: Abu Ghraib 3; AGRI S.: AGRI-saaten; B.: Barcelona; CLA: Carnation leaf agar; CZA: Czapek Dox agar; D: Dair district;
DRBC: Dichloran rose Bengal agar; FCR: Fusarium crown rot; FHB: Fusarium head blight; H: Huwair district; HM: Al-Hammar marshland; HPDA: Half potato dextrose agar; ITS: Internal transcribed spacer; MEA: Malt extract agar; MGA: Malachite green agar; ML: Maximum likelihood; ML1: Talha district/ marshland 1; ML2: Talha district/marshland 2; MSP: Modienh district/salt project region; MSR: Modienh district/Salih River region; N: Nashwa district; PCR: Polymerase chain reaction; PDA: Potato dextrose agar; QM: Qurna district/Mazearaa region; QPDA: Quarter potato dextrose agar; QRS: Qurna Research Station; R.: Rasheed; RBA: Rose Bengal agar; Res.22: Research 22; SDA: Sabouraud dextrose agar; SNA: Synthetic nutrient agar; TEF1a: Translation elongation factor 1 alpha; TI1: Thagar district/field 1; TI2: Thagar district/field 2; TI3: Thagar district/field 3; TK: Thagar district/Karakor region; WA: Water agar

\section{Acknowledgements}

The authors wish to especially thank Prof. Dr. Zaidan Omran Al-Mamory, lecturer in the Department of Microbiology, College of Medicine, Babylon University, Hilla, Iraq; Assist. Prof. Dr. Ali Aboud Shareef, lecturer in the Department of Biology, College of Education, Basra University; and Prof. Dr. Mohammed Hamza Abbas, lecturer in the Department of Plant Protection, College of Agriculture, Basra University, for their kind assistance and advice in reconstructing the phylogenetic trees in this study.

\section{Authors' contributions}

All work was done by $\mathrm{MH}$ under the supervision and advice of $\mathrm{MK}$. MH was a major contributor in writing the manuscript. Both authors read and approved the final manuscript.

\section{Funding}

The authors declare that they have no funding support during this study.

\section{Availability of data and materials}

Not applicable in this section.

\section{Ethics approval and consent to participate}

Not applicable in this section.

\section{Consent for publication}

Not applicable in this section.

\section{Competing interests}

The authors declare that they have no competing interests.

\section{Author details}

${ }^{1}$ Plant Pathology Laboratory, Department of Biology, College of Science, Basra University, Basra, Iraq. ${ }^{2}$ Department of Biology, College of Science, Basra University, Basra, Iraq.

Received: 12 April 2019 Accepted: 2 August 2019

Published online: 27 August 2019

\section{References}

Akinsanmi OA, Mitter V, Simpfendorfer S, Backhouse D, Chakraborty S (2004) Identity and pathogenicity of Fusarium spp. isolated from wheat fields in Queensland and northern New South Wales. Aust J Agric Res 55(1):97-107

Alvarez CL, Somma S, Moretti A, Fernandez Pinto V (2010) Aggressiveness of Fusarium graminearum sensu stricto isolates in wheat kernels in Argentina. J Phytopathol. 158:173-181

Aoki T, O'Donnell K (1999) Morphological and molecular characterization of Fusarium pseudograminearum sp. nov., formerly recognized as the group 1 population of F. graminearum. Mycologia:.597-609

Bluhm BH, Flaherty JE, Cousin MA, Woloshuk CP (2002) Multiplex polymerase chain reaction assay for the differential detection of trichothecene-and fumonisin-producing species of Fusarium in cornmeal. J Food Prot 65(12): 1955-1961

Bottalico A, Perrone G (2002) Toxigenic Fusarium species and mycotoxins associated with head blight in small-grain cereals in Europe. Mycotoxins in Plant Disease. Springer, pp 611-624

Braithwaite M, Alexander B, Adams R (1998) Nationwide survey of pests and diseases of cereal and grass seed crops in New Zealand. 2. Fungi and 
bacteria. Nationwide survey of pests and diseases of cereal and grass seed crops in New Zealand 2 Fungi and bacteria, pp 51-59

Braun HJ, Atlin G, Payne T (2010) Multi-location testing as a tool to identify plant response to global climate change. Climate Change Crop Prod 1:115-138

Burgess LW, Backhouse D, Summerell BA, Swan L (2001) Crown rot of wheat. In: Summerell BA, Leslie JF, Backhouse D, Bryden WL, Burgess LW (eds) Fusarium: Paul E Nelson Memorial Symposium. APS Press, St. Paul, pp $271-$ 294

Chakraborty S, Liu C, Mitter V, Scott J, Akinsanmi O, Ali S et al (2006) Pathogen population structure and epidemiology are keys to wheat crown rot and Fusarium head blight management. Australas Plant Pathol 35(6):643-655

Demeke T, Clear RM, Patrick SK, Gaba D (2005) Species-specific PCR-based assays for the detection of Fusarium species and a comparison with the whole seed agar plate method and trichothecene analysis. Int J Food Microbiol 103(3): 271-284

Food and Agriculture Organization of the United Nations (FAO). Database Results, Geneva. 2018

Gale LR (2003) Population structure of Fusarium species causing head blight of grain crops. In: Leonard KJ, WRe B (eds) Fusarium head blight of wheat and Barley. APS Press, St. Paul, pp 120-143

Gale LR, Chen L-F, Hernick CA, Takamura K, Kistler HC (2002) Population analysis of Fusarium graminearum from wheat fields in eastern China. Phytopathology. 92:1315-1322

Gale LR, Ward TJ, Balmas V, Kistler HC (2007) Population subdivision of Fusarium graminearum sensu stricto in the upper Midwestern United States. Phytopathology. 97:1434-1439

Hameed M, Rana R, Ali Z (2012) Identification and characterization of a novel Iraqi isolate of Fusarium pseudograminearum causing crown rot in wheat. Genet Mol Res 11(2):1341-1348

Hogg AC, Johnston RH, Johnston JA, Klouser L, Kephart KD, Dyer AT (2010) Monitoring Fusarium crown rot populations in spring wheat residues using quantitative real-time polymerase chain reaction. Phytopathology. 100(1):49-57

Jurado M, Vázquez C, Marín S, Sanchis V, González-Jaén MT (2006) PCR-based strategy to detect contamination with mycotoxigenic Fusarium species in maize. Syst Appl Microbiol 29(8):681-689

Khudhair M, Melloy P, Lorenz DJ, Obanor F, Aitken E, Datta S et al (2014) Fusarium crown rot under continuous cropping of susceptible and partially resistant wheat in microcosms at elevated $\mathrm{CO}_{2}$. Plant Pathol 63(5):1033-1043

Khudhair MW, Aboud HM, Jumaah M (2015a) Recent thread diseases in wheat and barley in Iraq. LAP LAMBERT Academic Publishing. https://www.amazon. com/Recent-Thread-Diseases-Wheat-Barley/dp/3659766402, p 52

Khudhair MW, Aboud HM, Mustafa DJ, Shbar AK, Khalaf HS. Spatial distribution of Fusarium crown rot (FCR) and Fusarium head blight (FHB) in wheat and barley in the south and middle of Iraq In press. 2015b.

Kimura M (1980) A simple method for estimating evolutionary rate of base substitutions through comparative studies of nucleotide sequences. J Mol Evol 16:111-120

Koch H, Pringas C, Maerlaender B (2006) Evaluation of environmental and management effects on Fusarium head blight infection and deoxynivalenol concentration in the grain of winter wheat. Eur J Agron 24(4):357-366

Kumar S, Stecher G, Li M, Knyaz C, Tamura K (2018) MEGA X: Molecular evolutionary genetics analysis across computing platforms. Mol Biol Evol 35:1547-1549

Lahuf AA, Jaafar OH, Al-mosoy M, Hameed ZL, Li J (2018) First record of the crown rot fungus Fusarium equiseti affecting Triticum aestivum L. and Aptenia cordifolia in Iraq. Asian J Agri Biol 6(4):55543-55548

Lamprecht SC, Marasas WFO, Hardy MB, Calitz FJ (2006) Effect of crop rotation on crown rot and the incidence of Fusarium pseudograminearum in wheat in the Western Cape, South Africa. Aust Plant Pathol 35(4):419-426

Leslie J, Summerell B (2008) The Fusarium laboratory manual. Wiley

Leslie JF, Summerell BA (2006) The Fusarium laboratory manual. Blackwell publishing, Ames

Li X, Liu C, Chakraborty S, Manners JM, Kazan K (2008) A simple method for the assessment of crown rot disease severity in wheat seedlings inoculated with Fusarium pseudograminearum. J Phytopathol 156(11-12):751-754

Matny O, Bates S, Song Z (2017) Geographic distribution of Fusarium culmorum chemotypes associated with wheat crown rot in Iraq

Matny ON, Chakraborty S, Obanar F, AL-Ani RA (2012) Molecular identification of Fusarium spp causing crown rot and head blight on winter wheat in Iraq. J Agric Technol 8(5):1677-1690

Monds RD, Cromey MG, Lauren DR, Di Menna M, Marshall J (2005) Fusarium graminearum, F. cortaderiae and F. pseudograminearum in New Zealand: molecular phylogenetic analysis, mycotoxin chemotypes and co-existence of species. Mycol Res 109(4):410-420

Mulè G, Gonzalez-Jaen M, Hornok L, Nicholson P, Waalwijk C (2005) Advances in molecular diagnosis of toxigenic Fusarium species: a review. Food Addit Contam 22(4):316-323

Nelson P, Toussoun T, Marasas W (1983) Fusarium species: an illustrated manual for identification. The Pennsylvania State University Press, University Park e Londra, p 193

Niessen L, Schmidt H, Vogel R (2004) The use of tri5 gene sequences for PCR detection and taxonomy of trichothecene-producing species in the Fusarium section Sporotrichiella. Int J Food Microbiol 95(3):305-319

Parry D, Jenkinson P, McLeod L (1995) Fusarium ear blight (scab) in small grain cereals - a review. Plant Pathol 44(2):207-238

Sambrook J, Fritsch E, Maniatis T (1989) Molecular cloning: a laboratory manual. Cold Spring Harbor Laboratory Press

Smiley RW, Patterson LM (1996) Pathogenic fungi associated with Fusarium foot rot of winter wheat in semiarid Pacific Northwest. USA. Plant Dis 80:944-949

Wegulo SN, Bockus WW, Nopsa JH, De Wolf ED, Eskridge KM, Peiris KH et al (2011) Effects of integrating cultivar resistance and fungicide application on Fusarium head blight and deoxynivalenol in winter wheat. Plant Dis 95(5): 554-560

White TJ, Bruns T, Lee S, Taylor J (1990) Amplification and direct sequencing of fungal ribosomal RNA genes for phylogenetics PCR protocols, a guide to methods and applications. Academic Press Inc, San Diego, pp 315-322

Xu X, Nicholson P (2009) Community ecology of fungal pathogens causing wheat head blight. Annu Rev Phytopathol. 47:83-103

\section{Publisher's Note}

Springer Nature remains neutral with regard to jurisdictional claims in published maps and institutional affiliations.

\section{Submit your manuscript to a SpringerOpen ${ }^{\circ}$ journal and benefit from:}

- Convenient online submission

- Rigorous peer review

- Open access: articles freely available online

High visibility within the field

- Retaining the copyright to your article

Submit your next manuscript at $>$ springeropen.com 